\title{
A imagem e o exercício de um pensamento comunicacional hoje
}

\author{
The image and the exercise of the communicational \\ thinking today \\ ALINE VeríSSIMO MONTEIRO \\ Professora da Escola Superior de Propaganda e Marketing ${ }^{1}$ - RJ \\ Doutora em Comunicação e Cultura pela ECO/UFR. \\ E-mail: amonteiro@espm.br
}

Resumo

Desde o surgimento da escrita privilegiamos o visual em nossa comunicação, tanto na composição das mensagens quanto no desenvolvimento de tecnologias. No entanto, este visual tem dois modos de manifestação: sob a forma do texto, que privilegia o símbolo e sob a forma da imagem onde os índices e icones predominam. Essas duas categorias de signos e mensagens visuais têm posições distintas na história da evolução humana e funcionam segundo lógicas de representação divergentes. Contudo, encontram-se hoje reunidas em uma cultura marcada pela tecnologia digital e na vigência de um pensamento comunicacional. Este artigo apresenta um início de compreensão das passagens históricas e lógicas de um tipo de signo ou tipo de mensagem visual a outro, tentando entender como o pensamento comunicacional e a tecnologia podem explicar certo privilégio da imagem sobre 0 texto atualmente.

Palavras-chave: imagem, cultura comunicacional, pensamento comunicacional, comunicação e semiótica.

Do surgimento da escrita ao do código digital, passando pelo audiovisual, nossa cultura tem privilegiado o signo visual como forma de expressão. Na tentativa de identificar o que seria específico da atual compreensão e elaboração da comunicação visual, dois aspectos se destacam. O primeiro diz respeito a um cenário cultural marcado pelas redes tecnológicas que ditam os ritmos da produção, da circulação e da compreensão das informações nos processos comunicacionais. Tecnologias que, como veremos, criam um cenário onde vigora o que denominamos um pensamento comunicacional, qual seja, a aceleração, a interação e a simulação como os regimes de exercício do tempo, da comunicação $e$ do conhecimento. Decorrente dessa base tecnológica, esses ritmos tomam a forma do excesso e da velocidade, os quais, por sua vez, impõem um contexto de alta competitividade entre as informações na busca de uma comunicação eficiente. $\mathrm{O}$ segundo se refere aos tipos de signos visuais utilizados nessa disputa entre informações, onde dois pares de categorias divergentes se destacam: textual e imagética ou, de outro modo, simbólica e icônico-índicial. Nesse contexto de excesso e disputa, ambas as categorias se fazem presentes, apesar de representarem segundo lógicas distintas e ocuparem pontos opostos na evolução do domínio cultural dos signos: o imagético e o icônicoindicial sendo os mais primitivos e o textual e o simbólico os mais elaborados culturalmente. Por um lado, desenvolvemos códigos como as línguas e chegamos a tal ponto de radicalização da arbitrariedade simbólica que produzimos o código digital, o qual, pode-se dizer, chega a
${ }^{1}$ Escola Superior de Propaganda e Marketing - RJ, Rua do Rosário, 90 - Centro, Rio de Janeiro/RJ CEP 20041-002. 
adotar o sinal no lugar do signo. Por outro, a liberdade e a sofisticação na produção de imagens permitidas por esse mesmo código digital, nos permite aproximar essas imagens cada vez mais de uma presença realista, a ponto de levarmos a discussão aos termos de uma disputa ou substituição do real pelo virtual, ou da realidade por uma simulação. ${ }^{2}$ $\mathrm{O}$ que pretendemos ao longo deste artigo é apresentar o início de uma análise dos caminhos que nos levaram a - após percorrermos evolutivamente o caminho do ícone e do índice ao símbolo -, como que a fazer o caminho de volta, neste século XXI - indo do texto à imagem. Neste primeiro momento, abordaremos características de cada categoria de signos e também o exercício do pensamento comunicacional para nos auxilia a compreender essa estória de passagens e produções de diferentes tipos de signos e direções de percurso na utilização desses em nossa cultura. Nos parece, até o momento, que a aproximação da experiência do tempo da aceleração e da simultaneidade; a aproximação da comunicação da interação; e a aproximação da atividade do conhecer da atividade de criação e simulação, simultaneamente exigem e estimulam o trabalho com as imagens, uma vez que elas atenderiam em larga escala a esses três regimes, ou seja, ao pensamento comunicacional.

Do icônico-indicial ao simbólico

${ }^{2}$ D. Bougnoux vai identificar esse movimento afirmando que na contemporaneidade há uma paradoxal convivência da progressão cultural simbólica com a regressão estética indicial (1994, 67-72). autor dessa tipologia com sua fenomenologia. Tal como Santaella nos descreve, os fenômenos do mundo se dividem segundo três elementos formais para Peirce: fenômenos de primeiridade, que envolvem, sobretudo, as qualidades e os sentimentos; de secundidade, onde temos relações de causa e efeitos e de dependência na existência; e de terceiridade, onde as ações da inteligência e de generalização estão presentes. Apoiada nessa fenomenologia, a semiótica peirceana descreve três tipos de relação dos signos com os objetos que eles representam: de semelhanças de qualidades com o objeto, caso em que o signo será um ícone; de dependência existencial e causal com o objeto, teremos então um índice; de determinação lógicoconceitual e convencional com o objeto, caso do símbolo. Ainda segundo nos descreve L. Santaella, qualquer existente pode funcionar como signo e sua classificação enquanto ícone, índice e símbolo só será possível na definição de sua relação com o objeto, relação constitutiva do signo uma vez que, para Peirce, o signo é composto pela tríade: signo-objeto-interpretante. Sendo assim, é preciso esclarecer o porquê de estarmos identificando os ícones e os índices à imagem e o símbolo ao texto em nossa categorização.

Dois motivos ressaltamos pra nossa opção no que diz respeito à imagem, ambos com base ainda em Peirce, pois, como ressalta U. Eco, se examinarmos "as distinções triádicas do signo propostas por Peirce, observaremos que a cada uma das definições do signo pode corresponder um fenômeno de comunicação visual" (op. cit., p. 98). O primeiro diz respeito aos ícones. Se é verdade para a semiótica peirceana que qualquer existente 
pode funcionar como signo de qualquer ordem, a depender de todos os elementos de sua tríade, também é verdade que há predisposições, otimizações e privilégios. As cores, por exemplo, são qualidades do mundo, e sendo fenômenos que existem, podem funcionar como signo qualquer. Assim, o vermelho pode em nossa cultura simbolizar a proibição de seguir em frente nos sinais de trânsito. Sendo a relação da cor vermelha com o objeto (o conceito proibição), uma relação conceitual, legal, intelectual: o vermelho é um símbolo nesse caso. Mas é fato que essa cor é também aquele elemento que melhor pode representar a qualidade vermelha dos objetos vermelhos do mundo, e por suas qualidades de intensidade e de comprimento de onda também representa bem sentimentos e sensações que são provocados por sua presença no mundo. Desta forma, as qualidades se prestam melhor a serem quali-signos icônicos, a funcionarem por semelhança na representação das qualidades do mundo. As imagens, que para muitos são sinônimos de ícones, sendo formadas por qualidades - formas, cores... - são aquelas que melhor representam por semelhança as qualidades do mundo ou de relações, como no caso dos gráficos e esquemas, por exemplo. Nas palavras de U. Eco:

“O signo icônico pode, portanto, possuir entre as propriedades do objeto, as óticas (visíveis), as ontológicas (pressupostas) e as convencionais (modelizadas, sabidamente inexistentes, mas eficazmente denotantes, exemplo: os raios de sol em forma de varetas). Um esquema gráfico reproduz as propriedades relacionais de um esquema mental.." (op. cit., p. 107).
O segundo se refere aos índices, e aqui, nossa filiação a tipologia de peirceana é mais fundamental ainda, pois é segundo ela que um tipo específico de imagem como a fotográfica e todas aquelas que tecnologicamente são desdobramentos dela é rigorosamente classificado como índice. Roland Barthes faz extensa discussão e defesa da fotografia como índice em seu ótimo A Câmara Clara (1981), onde a relação da fotografia com o instante e a morte se devem justamente ao fato de ela ser um "indício do real", uma "pegada de luz" deixada pelo fenômeno, "um vestígio deixado sobre uma superfície especial pela combinação de luz e ação química" (METZ, 1985, p. 82 apud L. SANTAELLA, 2001, p. 121), tal como uma pegada deixada na areia pela passagem de alguém. E é por essa dependência existencial de certas imagens com seus referentes reais ou, de outro modo, por essa certa insistência e captura do real pelas imagens, que o faz parecer simultaneamente exterior e interior a elas, que as aproximamos dos índices.

Ainda seguindo a semiótica peirceana, argumentos complementares aos dois anteriores justificam a aproximação do texto com o símbolo. Dentre os elementos que podem significar por ação intelectual, convencional, conceitual e generalizante, a língua, sobretudo em sua versão escrita, é o elemento simbólico por excelência. Não há em seus fonemas, monemas e sintagmas qualquer semelhança com o referente ou o significado conceitual. Na escrita, ainda mais, excluímos os traços de iconicidade e indicialidade que a oralidade mantinha pela presença da voz e do corpo e que implicava em fazer da performance a face determinante da comunicação. A escrita desencarna a 
mensagem, confere-lhe independência, permanência, objetividade e racionalidade.

\begin{abstract}
"A passagem da tradição oral para a tradição escrita comporta uma mudança radical no tipo de mensagem transmitida: essa já não é mais dependente de quem a envia e da discrição de quem recebe, porém fica à disposição de qualquer pessoa que a deseje ler. Pode ser relida, meditada, analisada; adquire, portanto, durabilidade, profundidade e clareza" (B. GIOVANNINI apud G GIOVANNINI, 1987, p. 28).
\end{abstract}

A escrita acentua as características simbólicas da língua, sua arbitrariedade e extremo controle, sobretudo a escrita alfabética, com sua dupla articulação e suas regras gramaticais. Eis porque U. Eco dirá que o código lingüístico é um código forte, sendo a língua "um sistema, isto é, tem uma estrutura suscetível de ser descrita em abstrato, e representa um conjunto de relações" (op. cit., p. 30), dotada de coerência interna; e os códigos visuais icônico e indiciais, ainda que $o$ autor defenda suas existências e também a presença de convenções em seus funcionamentos, serão sempre códigos fracos.

No continuum icônico, não se recortam traços pertinentes discretos e catalogáveis de uma vez por todas, mas os aspectos pertinentes variam [...] os signos do desenho não são elementos de articulação correlatos aos fenômenos da língua porque não têm valor posicional $e$ oposicional, não significam pelo fato de aparecerem ou não aparecerem; podem assumir significados contextuais [...] sem terem significado próprio [...]. Eis em que sentido os códigos icônicos, se é que existem, são códigos fracos. (ECO, op. cit., p. 114).

Do texto ao digital e o pensamento comunicacional

Em sua apresentação do desenvolvimento da comunicação da pré-história à invenção da escrita, Bárbara Giovannini salienta que "a capacidade de traduzir em conceitos os elementos da vida cotidiana, de representação da realidade através de símbolos" (op. cit., p. 26) deveria estar presente desde que os primeiros grupos humanos se formaram e começaram a desenvolver o que se pode chamar de cultura: cooperação grupal, utensílios, seus usos e manuseios, pinturas. No entanto, na apresen-tação da autora, os motivos e os elementos que deram origem à linguagem, entendida como essa capacidade simbólica, são ainda objetos de debates e discórdias. O que se afirma como certo na obra da autora é a que, entre 6000 e 3000 a.C., a passagem do estado de caçador para o de agricultor feita pelo homem no período Neolítico, fez a comunicação se desenvolver no que diz respeito às línguas e ao registro escrito de informações, considerando-se que entre 5000 e 4000 a.C. os Sumérios tenham inventado a escrita. Ligada a necessidades comerciais e políticas a escrita desde sua origem serviu à organização e ao controle, estando também restrita a pequenos grupos, sendo elemento de segregação e elitização. B. Giovanninni salienta que a passagem da oralidade à escrita serviu à passagem da aldeia à cidade ou conglomerado urbano. Somente o registro autônomo, permanente e codificadamente organizado pôde permitir a gestão e a complexificação das relações comerciais, políticas, militares e 
sociais representadas pelas grandes concentrações demográficas.

Nesse sentido, podemos entender que as culturas que investiram na codificação simbólica escrita das línguas, sobretudo a alfabética, seguiram desenvolvendo o estudo $\mathrm{e}$ a reflexão sobre o signo simbólico em sua versão lingüística, e a capacidade de acumular, produzir, distribuir e organizar informações e de otimizar e ampliar comunicações. A escrita alfabética permitiu a instalação do pensamento lógicoracional, da linearidade, da história evolutiva e do progresso como modos de compreender e ordenar o mundo. $O$ texto é lido e escrito linearmente, elemento por elemento. As cores, formas e emoções que descreve são apresentadas concei-tualmente, $\mathrm{e}$ apenas após decodificação intelectual de seus significados podem afetar nossos sentidos provocando sentimentos e sensações. ${ }^{3}$ Dominar o código linguíistico é condição essencial da emissão e da recepção de sua informação e da efetivação de qualquer comunicação. O olho, órgão privilegiado nesse universo visual escrito, éo "olho da razão", "do espírito letrado", e não o olho de carne e osso, órgão de sentido e de emoção. Por todas essas características, a escrita alfabética, ao preço de desencarnar a mensagem, instala o reino do símbolo, lança a humanidade ao progresso e à reflexão crítica, sendo essas as características distintivas do homo sapiens, como defende G. Sartori (2002). A ciência, a teoria, a técnica se apossaram de todas as instâncias da vida: ciências biológicas, matemáticas, sociais, humanas, políticas, do direito: todas com seus instrumentos teóricos e técnicos a definirem as melhores ações para conduzir a humanidade ao progresso e cumprir o destino evolutivo da história.

Desse investimento simbólico, reflexivo, técnico, científico e matemático chegamos ao desenvolvimento do código digital binário, reino da arbitrariedade, da plena convenção entre humanos, seres vivos e máquinas, onde nada mais de analogia, logo, de iconicidade e indicialidade se faz presente. Nem sob a forma de imagem mental tal como descreve U. Eco e L. Santaella. ${ }^{4}$ Código auto-referente, auto-suficiente que abandona a representação, a captura e a insistência do real e adota sua simulação e virtualização como modos de funcionamento. (Cf. E. Couchot in A. Parente (org.), 1993 e P. Levy, 1995). E é, a partir dessa digitalização que surge o que entendemos por cultura comunicacional e pensamento comunicacional.

O processo geral de digitalização vai desencadear modificações no que entendemos ser os regimes de exercício do tempo, da comunicação e do conhecimento. Isto porque, ao codificarmos e decodificarmos o mundo segundo a lógica da binariedade digital, podemos traduzir todo e qualquer tipo de signo-comunicação em sinal-informação: imagens, sons, formas, cores, texturas, movimentos, letras: todos transformados em seqüências de 0 e 1 , transmitidos à velocidade da luz, percorrendo e transformando as distâncias espaciais em instantes temporais. Esse processo faz com que passemos a experimentar o tempo, esse que apreendemos pelas transformações e mecanismos de mudança, como tempo real e aceleração. Sendo esses fenômenos também responsáveis por fazerem coincidir as concepções cronológicas lineares de passado, presente e futuro, de modo que esse último se precipite sobre os outros dois como determinação e predeterminação.

Um mundo codificado, digitali-
${ }^{3}$ Cf. além de Giovannini, op.cit., Lévy, 1993 e McLuhan, 2001.

4 "O mundo das imagens se divide em dois domínios. O primeiro é o domínio das imagens como representações visuais (...) O segundo é o domínio imaterial das imagens na nossa mente (...) Ambos os domínios de imagem não existem separados, pois estão inextricavelmente ligados já na gênese. Não há imagens como representações visuais que não tenham surgido de imagens na mente daqueles que as produzem, do mesmo modo que não há imagens mentais que não tenham origem no mundo concreto dos objetos visuais." (SANTAELLA, 2001, p. 15). 
zado, faz com que a comunicação se estabeleça segundo seus fluxos informático-temporais, afastando-se do modelo linear excludente da seqüência emissor-mensagem/ canal-receptor, e adotando a recursividade e a complexidade da comunicação interativa. Em interação, as barreiras naturais entre os diferentes sistemas são ultra-passadas por traduçõesmediações sempre possíveis através de mecanismos de interfaces, e a circularidade causal colide as figuras do emissor, da mensagem e do receptor, termos que agora se codefinem contextualmente.

Da mesma forma, estando integrado de modo interativo com o mundo pelo partilha dos códigos e dos mecanismos de tradução-mediação, $o$ ato de conhecimento, antes privilégio humano e capturado em um modelo também linear excludente de evolução, progresso e descoberta da verdade, passa a ser um ato coletivo, de sistemas integrados em interação, os quais não mais descobrem uma verdade pré.existente do mundo, mas codificam e decodificam virtualidades, simulando possibilidades do real. Conhecer toma a forma da ação de simulação criativa, ação de informação, de conferir formas a esse mundo-código dotado, desde então, não mais de essência, mas de plasticidade.

0 retorno da imagem: uma aliada do pensamento comunicacional?

Como vimos até aqui, o excesso de informação e a rede tecnológica que lhe fornece sustentação são características estruturais da cultura atual. Essa base tecnológica responde também pela forma predominantemente visual adotada por essas informações. No entanto, esse excesso de informação em imagem e texto produzido e posto em circulação pelas tecnologias tem gerado discussão sobre os caminhos evolutivos que a cultura atual está tomando. Do surgimento da escrita à invenção da imprensa, temos contado uma história evolutiva da tecnologia e das produções culturais. Contudo, antes da revolução digital, o desenvolvimento tecnológico promoveu o resgate do icônico e do indicial, através da imagem. Resgate que, desde seus primeiros sinais provocou críticas por seu antagonismo com a lógica simbólica textual vigente e dominante até então. Do surgimento da fotografia, ao cinema e à tv, o aspecto evolutivo não tem sido mais ponto de acordo entre os teóricos. As concentrações urbanas, conquistas da escrita, passaram a ser entendidas como multidão e massa, e a uniformização e o excesso de circulação de imagens passaram a ser alvo de ataques à capacidade crítica, racional e reflexiva dos sujeitos, capacidades que foram privilegiadas e desenvol-vidas com a escrita. G. Sartori (op.cit.) é um dos que alertam, ao tratar da televisão, sobre o risco de a humanidade estar abrindo mão daquilo justamente que a diferencia e a levou a evolução: a reflexão através do manuseio dos símbolos, entendidos por ele como o signo lingüístico ou verbal. Para ele estamos correndo o risco de deixarmos de ser homo sapiens para nos tornarmos homo videns.

Santaella destaca uma característica da imagem, além daquelas já apontadas por U. Eco, que serve à compreensão do pessimismo de Sartori diante da profusão de imagens em nossa cultura. Profusão em muito ampliada quando a digitalização captura em sua lógica tanto o texto quanto a imagem, e permite, em termos tecnológicos, a convergência das mídias, o desen- 
volvimento dos multimeios, dos hipertextos e de uma cibercultura. Como bem salienta a autora, "em comparação com a língua, a semântica da imagem é particularmente polissêmica" (SANTAELLA, 2001, p. 53). A polissemia da imagem, sustentada pela fraqueza de seu código, permite que qualquer um, sem necessidade de um domínio de regras e elementos rigoroso como o necessário para a leitura, possa apreender um sentido de sua presença (não o sentido, diria Sartori). Por isso G. Sartori argumenta que a predominância da imagem como elemento de comunicação de uma cultura é perigoso. Para ele, "a palavra é um símbolo totalmente resolvido naquilo que significa, naquilo que faz entender", enquanto que a imagem "é pura representação visual, basta vê-la para entendê-la" (G. SARTORI, op. cit., p. 21-22), ela apresenta, mas não explica ou esclarece. Por sua polissemia não exige maiores reflexões sobre o seu sentido intelectual e conceitual. Ela apela ao olho biológico, dispensando o olho do espírito. Enquanto a mensagem escrita exige uma decodificação intelectual de sua informação, a mensagem imagética é autoevidente. Por esse mesmo motivo, segundo $o$ autor, alguns defendem a cultura da imagem como sendo mais democrática do que a do texto. No entanto, para o autor, o que se democratiza com essas imagens é uma sub-cultura, o que faz dessa democratização mais perda do que ganho (Ibidem, p. 27).

Outra característica da imagem que a polariza em relação ao texto é sua impossibilidade de promover o que serve de base para o pensamento reflexivo, crítico e analítico: a metalinguagem, o que inclui também a ausência da negação e da temporalidade. Não é possível negar através de um signo que mostra, que traz à presença. Da mesma forma que não é possível falar do que passou e virá, do já não está mais presente e do que ainda não está presente, trazendo sua imagem à presença. A imagem, sendo uma representação semelhante ao objeto ou que captura e mantém uma insistência do objeto presente, não permite representar os deslocamentos temporais e, portanto, não favorece a compreensão gerada pelo pensamento abstrato e evolutivo. A imagem apresentará sempre um exemplo, um caso particular, um cachorro específico e como que concreto, com características e particularidades; jamais permitirá representar o conceito ou a idéia de cachorro como um universal, geral, composto apenas de elementos essenciais. Mas, se a imagem apresenta mesmo tantos riscos e desvantagens, porque voltamos a ela e tanto a valorizamos? Não haverá nela qualquer conquista que nos permita não considerar sua presença como um retrocesso?

D. Bougnoux nos fornece algumas pistas neste sentido, se associarmos seu pensamento com nossa compreensão da vigência de um pensamento comunicacional na atualidade. $\mathrm{O}$ autor nos alerta para o fato de que na contemporaneidade há uma paradoxal convivência da progressão cultural simbólica com a regressão estética indicial. Para entender esta convivência paradoxal é preciso fazer um pequeno recuo e esclarecer a distinção feita pelo autor entre comunicação e informação.

Para D. Bougnoux, o par comunicação / informação se diferencia e se completa, respectivamente, tal como os pares enunciação / enunciado, relação / conteúdo e comunicação analógica / comunicação digital, estes últimos propostos pela Escola de Palo Alto. Partindo 
da distinção entre comunicação analógica e comunicação digital de Palo Alto, D. Bougnoux, recorrendo à semiótica de C. S. Peirce, aprimorará esta distinção fazendo corresponder a comunicação ao universo analógico da enunciação, da relação, do uso dos índices e ícones; e a informação ao universo digital dos enunciados, dos conteúdos, do uso dos símbolos, tanto linguísticos quanto numéricos. Desta forma, a dimensão do rumor, do ruído que permanece aquém e além de toda informação, que compõe o espaço tumultuado e competitivo que um discurso percorre, é a dimensão da comunicação. Toda informação se faz a partir e através da comunicação, assim como a todo enunciado corresponde uma condição de enunciação e todo conteúdo é trocado em uma relação.

Para D. Bougnoux, a progressão cultural segue o caminho do desenvolvimento e do domínio da ordem simbólica, portanto, informacional. Já as relações mais primitivas, aquelas organizadas segundo os afetos e as sensações, compõem o campo da comunicação. Seguindo esta distinção, a evolução das mídias de massa e de alta velocidade, dos dispositivos de comunicação informacionais, apesar de ser fruto da evolução simbólica e de eles trabalharem com códigos digitais - ou seja, simbólico-numéricos -, traz de volta à cultura a dimensão estética e do contato da comunicação analógica, sobretudo na forma indicial.

As comunicações à velocidade da luz, a instalação de realidades em tempo real, a transmissão ao vivo são responsáveis por confundir a dimensão do enunciado e da enunciação. Elas dificultam sua percepção como signos e fazem as vezes do próprio fato: o discurso se confunde com a realidade, a relação com o conteúdo, o emissor com o receptor. Neste contexto, a informação passa por comunicação e a comunicação se torna irremediavelmente pragmática. Não é por outro motivo que a sociedade da informação é também a da cultura comunicacional.

As imagens assumem particular importância neste contexto, e uma analogia com o universo dos sonhos e do inconsciente freudiano é construída pelo autor. Segundo D. Bougnoux, o regime das representações da comunicação analógicoindicial, instalado pela tecnologias digitais, segue o regime das representações inconscientes descritas por $\mathrm{S}$. Freud. No curso da enxurrada de imagens, no fluxo torrencial de signos que apelam aos sentidos como se vestígios da presença concreta dos fatos fossem, a ordem primária do inconsciente vigora, e com ela: a ausência da negação, da flexão temporal, do relevo lógico, da linearidade, do universal. O índice é sempre particular, no máximo é um exemplo do universal.

Nesse aspecto, $o$ autor parece dar razão ao diagnóstico de G. Sartori, uma vez que o regime o universo da comunicação analógico-indicial seria como que oposto ao esforço cognitivo exigido pelo rigor científico; ao universo da abstração conceitual; à lógica linear do raciocínio científico averso a contradições; à universalidade da lei, do axioma, do conceito; à "maturidade" discursiva da linguagem científica marcada pela oposição e pela arbitrariedade simbólica. A lógica da imagem faria com que nos aproximássemos dos textos buscando a mesma facilidade de recepção e afetação da associação livre, do pensamento metonímico e indicial do universo da "comunicação onírica".. Acostu-mados com a disponibilidade infinita de criação de imagens e de 
atualização de virtualidades criada pelos dispositivos informáticos; com a estranha materialidade conferida às abstrações por meio das simulações tecnológicas e das seduções publicitárias, estaríamos no caminho de sempre procurar imagens, exemplos, alguma materiali-zação do imaginário permitida hoje pela desmaterialização da infor-mação.

Contudo, este conflito entre o analógico-digital e o simbólico, sendo uma marca da cultura e sendo pensado na vigência de um pensamento comunicacional permitiria que uma análise diferente daquela que nos leva a considerar uma involução rumo à imaturidade intelectual-científica ou a criação de um homo ludens, como nomeia G. Sartori (op. cit.). Reconhecendo a adoção da imagem do contexto cultural e dos dispositivos tecnológicos e cognitivos que nos cercam, é preciso acolher a busca por imagens exigências da cultura.

Criar imagem, "materializar" o imaginário abstrato aparece como o diferencial de nossa cultura comunicacional, aquilo no que insistimos e nos formamos. Se pensarmos em termos de uma "cibercultura", como bem descreveu Lévy (1999), o tratamento estético indicial (rico em imagens, sons e apelos táteis que clamam por manipulação e interação) aparece como uma exigência da construção das mensagens, das interfaces, da organização da comunicação. ${ }^{5}$ Comunicar com velocidade e com a maior extensão possível em um mundo globalizado em rede exigiria a utilização de um código sim mais democrático, mais flexível em termos de decodificação e simultaneamente, com maior vínculo com o real, mesmo que um real simulado. Não por outro motivo os computadores se popularizaram valorizando a figura do usuário, aquele que não domina a linguagem simbólica da máquina, construindo softwares onde a iconografia e a indicialidade dos gestos via mouse são os modos de operação privilegiados. Desta forma, é preciso que assumamos o compromisso com esta comunicação analógico-digital; com os sentidos e os afetos que insistem por trás da lógica e da razão; como a comunicação por trás da informação. Conciliar estes dois regimes é o desafio. Enfrentá-lo somente será possível se abandonarmos a visão linear hierárquica na comparação entre os regimes de signos e assumirmos suas diferenças como positividades.

\begin{abstract}
Since the emergence of writing we favor the visual in our communication, both in the composition of messages and in the development of technologies. However, this visual has two modes of expression: in the form of text, which favors the symbol and in the form of the image where the indices and icons dominate. These two categories of visual signs and messages have different positions in the human evolution history and operate under divergent logics of representation. Nevertheless, they are now grouped in a culture marked by digital technology and the domain of a communicational thinking. This article presents a beginning of understanding of the historical and logical passages of a type of sign or type of visual message to another, trying to understand how the communicational thinking and the technology may explain a certain privilege of image over text today.

Keywords: image, communicational culture, communicational thinking, communication and semiotic.
\end{abstract}

\section{Referência}

BARTHES, R. A camara clara. Lisboa: Edições 70, 1981.

\begin{abstract}
${ }^{5}$ S. Johnson, em A cultura da interface, nos fornece um excelente exemplo de como a criação de interfaces e de um espaço informacional, um ciberespaço, envolve o trabalho com ícones e índices e o afastamento da lógica simbólica da leitura, da escrita e da organização de papéis.
\end{abstract}


BOUGNOUX, D. Introdução às ciências da informação e da comunicação. Petrópolis, RJ: Vozes, 1994

ECO, U. A estrutura ausente. São Paulo: Perspectiva, 2001.

GIOVANNINI, G. Evolução na comunicação: do sílex ao silício. Rio de Janeiro: Nova Fronteiro, 1987.

LÉVY, P. Cibercultura, São Paulo: Editora 34, 1999.

As tecnologias da inteligência: o futuro do pensamento na era da informática. Rio de Janeiro: Ed. 34, 1993.

MCLUHAN, M. Os meios de comuni- caçào como extensões do homem, São Paulo: Cultrix, 2001.

SANTAELLA, L. Matrizes da linguagem e pensamento: Sonora, visual, verbal. São Paulo: Iluminuras/FAPESP, $2002 \mathrm{a}$.

Semiótica aplicada. São Paulo: Pioneira Thompson, 2002b.

SANTAELLA, L. \& NÖTH, W. Imagem: cognição, semiótica, mídia. São Paulo: Iluminuras, 2001.

WATZLAWICK, P.; BEAVIN, J. H. \& JACKSON, D. D. Pragmática da comunicação humana: um estudo dos padrões, patologias e paradoxos da interação. São Paulo: Ed. Cultrix, 1993. 